\title{
Retracted: Analysis of Sports Event Management Teaching from the Perspective of Multimedia considering Multiobjective Teaching Optimization Algorithm
}

\author{
Advances in Multimedia \\ Received 5 November 2022; Accepted 5 November 2022; Published 22 November 2022 \\ Copyright (C) 2022 Advances in Multimedia. This is an open access article distributed under the Creative Commons Attribution \\ License, which permits unrestricted use, distribution, and reproduction in any medium, provided the original work is \\ properly cited.
}

\begin{abstract}
Advances in Multimedia has retracted the article titled "Analysis of Sports Event Management Teaching from the Perspective of Multimedia considering Multiobjective Teaching Optimization Algorithm" [1] due to concerns that the peer review process has been compromised.

Following an investigation conducted by the Hindawi Research Integrity team [2], significant concerns were identified with the peer reviewers assigned to this article; the investigation has concluded that the peer review process was compromised. We therefore can no longer trust the peer review process, and the article is being retracted with the agreement of the editorial board.
\end{abstract}

\section{References}

[1] R. Wang, "Analysis of Sports Event Management Teaching from the Perspective of Multimedia considering Multiobjective Teaching Optimization Algorithm," Advances in Multimedia, vol. 2021, Article ID 3554715, 6 pages, 2021.

[2] L. Ferguson, "Advancing Research Integrity Collaboratively and with Vigour," 2022, https://www.hindawi.com/post/advancingresearch-integrity-collaboratively-and-vigour/. 


\title{
Analysis of Sports Event Management Teaching from the Perspective of Multimedia considering Multiobjective Teaching Optimization Algorithm
}

\author{
Rongrong Wang $(\mathbb{D}$ \\ Economics and Management School, Wuhan Sports University, Wuhan 430079, China
}

Correspondence should be addressed to Rongrong Wang; wangrongrong@whsu.edu.cn

Received 18 August 2021; Accepted 29 October 2021; Published 11 December 2021

Academic Editor: Zhendong Mu

Copyright (c) 2021 Rongrong Wang. This is an open access article distributed under the Creative Commons Attribution License, which permits unrestricted use, distribution, and reproduction in any medium, provided the original work is properly cited.

\begin{abstract}
At present, the combination of multimedia technology and physical education has been extensively applied, and the reform of sports event management has also attracted the attention of researchers. Reform and innovation have been carried out on the effective utilization of physical education resources and the image display of sports actions with great difficulties in the process of teaching and cross school and class synchronous learning, which has not only enriched the approaches and methods of sports management and teaching but also achieved certain effects.
\end{abstract}

\section{Introduction}

The continuous development of the Internet has also received many major applications and help in sports communication and education. The online sports video live broadcast industry has solved the problem that many big sports leagues cannot be broadcast live in real time [1-4]. With the increasing development of science and technology, the field of education has also been widely used. China's physical education is undergoing continuous reform and innovation, and multimedia education is especially important. Physical education teachers in higher vocational colleges in China are also actively exploring the use of multimedia to enhance and promote new physical education. In the practice of sports competition management education, compared with the teaching model of teachers, the multimedia model is more and more interesting. In particular, the coaches and models in the video have beautiful modeling leadership. The three-dimensional characteristics of multimedia sound color, shape, image, and figure are the description of knowledge, animation of specific actions, realistic video display, and so on, which show intuitive and impressive teaching content. With the participation of multimedia in
China's physical education teaching, students can entertain and have fun and at the same time achieve the effect of teaching while efficiently and accurately making students interested and at the same time improving all aspects of teaching.

\section{Feedback on the Application of Multimedia Technology in Physical Education}

The multiobjective teaching optimization algorithm is an integrated computer system with the collection of texts, audio, images, animation, videos, and other media information and is used as the primary resource for network education (Table 1). With the deepening in the ice-breaking of social and economic reforms, the socialist market economy with Chinese characteristics has been further developed, with the recognition of the world and formed an economic system based on market regulation, supplemented by government control, rational distribution of profits, and opening to the outside world in all aspects $[5,6]$. Social and economic reforms have also promoted the reform of the organization and management models of large-scale sports competitions. The mode of organizing game events has changed from the management model dominated by the 
TABLE 1: Storage formats of editing software for different materials in multimedia.

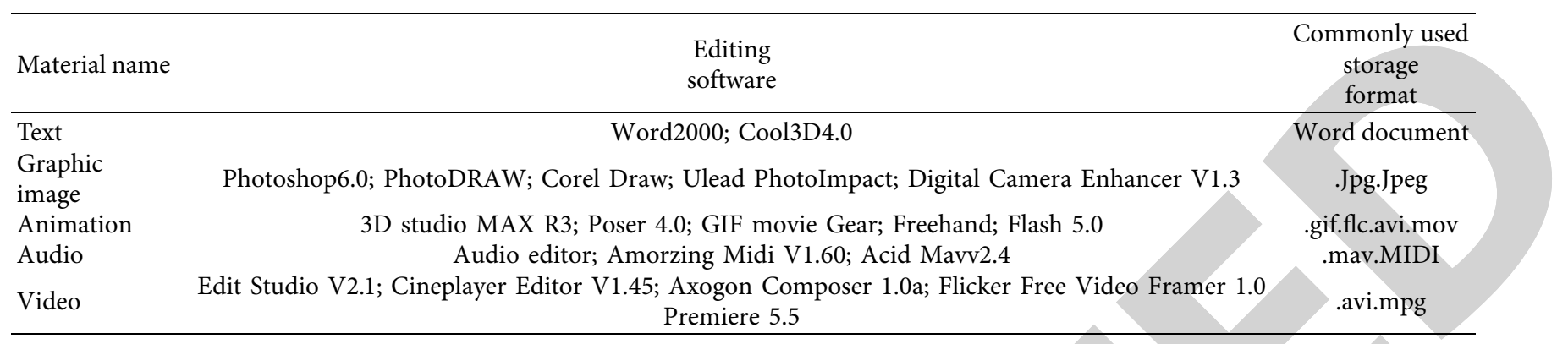

government to the competition model guided by the market. After the Beijing Olympics, the organization and management model of large-scale sports competitions has gradually shifted to a market-oriented model. For example, the 2015 International Champions Cup was introduced to China and sponsored by LeTV Sports, and the 2015 International Camping Competition was introduced and sponsored by Xingji Culture Communication Co., Ltd. In these events, the enterprise is the entity that organizes the competition and applies to the government for organizing the event based on the market situation. After review by the government, the enterprise applies to the owner of the competition for the right to organize the competition. The competition organization and management model guided by the market has emphasized the role and status of the market, where the government is responsible for management and supervision, and the enterprises in the market, as the competition entity, organize the competition and undertake a series of risks such as competition finance, legal affairs, and competition.

In the development and design of the multiobjective teaching optimization algorithm, the observation probability of the state conforms to the Gaussian distribution, and the logarithm is uniformly distributed; it has a highly significant influence on the score for the learning method while the probability of transition between states is concentrated [7]. As a result, its influence on the score for the learning method is small. If the data of a certain frame are concentrated, the probability value of a certain learning method is highly significant, but there may not be the global optimal learning method. At this point, the application of a fixed threshold value will exclude the optimal learning method, which can seriously affect the accuracy of recognition. The solution is to acquire the learning method with the highest and lowest scores among all learning methods in the current frame and use the method of dividing points to take the dynamic threshold value at the same time, as shown in the following:

$$
\begin{aligned}
P_{\min }\left(S_{t}\right) & =\min _{1 \leq i \leq N}\left(P^{\prime}(j)\right), \\
P_{\max }\left(S_{t}\right) & =\max _{1 \leq i \leq N}\left(P^{\prime}(j)\right), \\
c & =0.618\left(P_{\max }\left(S_{t}\right)-P_{\min }\left(S_{t}\right)\right) .
\end{aligned}
$$

In the above equations, $P^{\prime}(j)$ stands for the probability of learning method $j, P_{\min }\left(S_{t}\right)$ and $P_{\max }\left(S_{t}\right)$ stand for the worst learning probability and the optimal learning probability of state $S$ at the time $t$, and $c$ is the golden section point of the difference between them. It is then introduced into $P_{\max }\left(S_{t}\right)$ in (2)to obtain the threshold value.

Based on the data shown in Table 2 of the survey information, $58 \%$ of physical education teachers use multimedia in education students during the classes occasionally, which accounts for the largest proportion, while those who "never use multimedia in education" account for $23 \%$ and those who "use multimedia in education frequently" and "use multimedia in education all the time" account for the lowest proportion in the education methods. This indicates that in the process of physical education, high school teachers often pay little attention to education based on multimedia. Hence, the frequency of teaching class by multimedia is not high, and some teachers even ignore the education method based on multimedia when they complete their education tasks. $49 \%$ of the students surveyed said that their physical education teachers were "relatively unskilled" in operating multimedia equipment for class teaching, and $17 \%$ of the students said that their physical education teachers basically did not know how to operate multimedia equipment. The majority of students (accounting for 34\%) said that their physical education teachers were relatively proficient in operating the multimedia equipment, and only a few students said that their physical education teachers were very proficient. The poor proficiency in operating multimedia equipment has shown that the teachers lack knowledge on multimedia at present, which also directly affects the intuitive effects of multimedia education. Based on the content of the interviews, the expressions of the students, and the aforesaid data, it can be known that multimedia equipment has been popularized in the institutions of higher learning, and the education approach of applying multimedia in physical education has also been extensively implemented. So far, it is still in the early and unmature stages of development. Many schools have recognized the convenience of the education method based on multimedia. However, they have not paid enough attention or popularized the approach very actively.

\section{Application of Multimedia in the Sports Competition Management Education}

Some theoretical knowledge in sports can be taught in schools and stadiums. Students from multiple classes or departments can be gathered in a large classroom with 
TABLE 2: Feedback from college students on the current status of physical education based on multimedia.

\begin{tabular}{|c|c|c|c|}
\hline Problem & Option & Proportion (\%) & Number of people \\
\hline \multirow{4}{*}{$\begin{array}{l}\text { How often do your teachers of physical education at the college use } \\
\text { multimedia in } \\
\text { class? }\end{array}$} & Always & 3 & 18 \\
\hline & Often & 14 & 68 \\
\hline & Occasionally & 57 & 267 \\
\hline & Never & 22 & 105 \\
\hline \multirow{4}{*}{$\begin{array}{l}\text { What do you think of the proficiency of physical education teachers in the } \\
\text { operation of multimedia equipment at present? }\end{array}$} & Very proficient & 9 & 46 \\
\hline & Relatively proficient & 23 & 112 \\
\hline & Relatively unskilled & 48 & 224 \\
\hline & $\begin{array}{c}\text { Basically not able to } \\
\text { use it }\end{array}$ & & \\
\hline
\end{tabular}

multimedia facilities. The relevant class teacher can play multimedia or give the explanation based on the multimedia courseware [8-10]. This main advantage of this form of multimedia application is that it can make full use of the professional expertise of some physical education teachers, save the resources of other teachers, and create opportunities for the professional development and research of other teachers. In fact, the application of multimedia technology has a significant influence on the education and training of high school sports competition management. College sports education has also implemented transition from pure education to comprehensive training. The education approaches have also shifted from traditional experience of teachers and students to technical training. The competitive forms have become increasingly diversified. To sum up, multimedia technology has been extensively applied in all walks of life. The specific applications in high school sports are reflected in the following points, as shown in Figure 1. The application of multimedia technology in sports competition management education and training has offered new learning methods for sports learners. The application of multimedia technology in some sports, entertainment, and so on has dramatically reduced the injuries of sports. For example, athletes of dangerous sports such as skiing and racing can be trained indoors through multimedia technology to avoid avalanches, crashes, and other accidents. Multimedia technology has achieved a realm that cannot be achieved by the other objective elements. It can be used as an athlete's sparring partner, which has improved the athletes' odds to a certain extent. For some countries and regions where it is difficult to conduct training or for some athletes who can hardly reach the level of opponents, multimedia technology can address these issues effectively. In addition, multimedia technology can also be used to simulate natural sports venues so that people living in the city can experience nature and relax their bodies and minds.

\section{Relationship between the Application of Multimedia and the Reform of Sports Competition Management Education}

Based on the reality of the sports competition management education practice and the reform of higher vocational sports education, there is a relationship between the

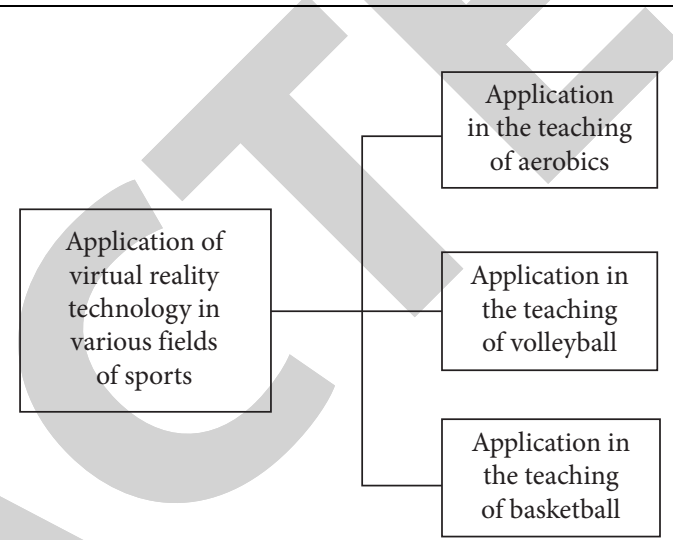

FIGURE 1: Specific application of multimedia technology in sports competition management education at colleges and universities and in virtual reality.

application of multimedia and the $t$ reform of sports competition management education in the aspects of means, approach, and support $[11,12]$.

4.1. Improvement of the Education Technology. Firstly, the application of modern education techniques has been improved among teachers. As higher vocational physical education teachers, they are required not only to master the use of various sports equipment and modern supporting facilities but also the use of multimedia education facilities. For example, in high school sports competition management education, the education courseware production, video editing, music selection, personal education video, or demonstration video recording can be experienced. Teachers are required to master the aforesaid techniques if possible based on the needs of sports competition management education. In addition, they are required to use them creatively based on the requirements of the school, physical education department, and personal education plans, such as the application of indoor gymnastics education, the application of theoretical lessons, and the application $e$ of high-quality education videos from other teachers or experts. Secondly, the teacher's own sports management and education technology has been improved. In the education practice of sports competition management, the application of multimedia technology is still deemed as a supplementary education approach; that is, it is mainly based on the practical education activities of physical 
education teachers by example. Hence, multimedia technology often plays a different role in the higher vocational physical education reform depending on the different education contents. In general, there are two types of applications. The first type is auxiliary application; that is, it is no longer used after supporting the teacher to complete the demonstration of the movement or improving the interest of students in learning, or it is used very frequently in a very short time in classroom education. The second type is the primary education method. As described in the above section, the whole class is completed based on multimedia. Hence, it has directly enriched the classroom education methods adopted by the teacher.

4.2. Broad Horizons of Education. With the advancement of modern information and communication technologies, multimedia technology has also implemented networking and remote applications; it has broadened the horizons of education and learning, for both teachers and students, based on the actual situation of education. Firstly, it offers a broad vision of professional knowledge. Due to the super large capacity of multimedia education contents relative to that in the classroom education by teachers, relatively professional, accurate, and standardized movement images or technical analysis will be used for presentation, whether in the education of theoretical knowledge or the demonstration education of related technical skills. This type of education method has broken through the limitation in the education by teachers and allows them to broaden the learning methods, learning content, and horizons in all aspects. Secondly, education technology features a broad vision. This type of technical vision includes the application technology for equipment and facilities related to multimedia, the development and application technology of multimedia software, the development of multimedia courseware technology, the playback technology of multimedia contents, the recording technology of multimedia videos, and so on. When students are accepting the fruitful results of multimedia production, teachers should also introduce to students the other technologies related to multimedia as appropriate. In this way, students can understand various education technologies and the relationship between modern information technology, network technology, and computer technology and learn to carry out self-study by using these technologies.

\section{Case Analysis of Sports Competition Management Education from the Perspective of Multimedia}

5.1. Analysis of Education Data on Sports Competition Management. For data samples of the big data in the database for the sports competition management behavior characteristics [13-15], the statistical characteristics of the sports competition management behaviors are analyzed. Firstly, the variables are determined. The influencing factors of the sports season are selected, and the corresponding variables are defined as $Z_{i}(i=1,2, \ldots, 8)$; the importance of education for sports competition management behaviors is defined as $W_{k i}(i=1,2, \ldots, 6 ; k=1,2, \ldots, 6)$; the social input of sports competition management behaviors is defined as $X_{i j}(i=1,2, \ldots, 6 ; j=1,2, \ldots, 8)$; the inertia weight is 0.78 , the coefficient of correlation $(R)$ is 0.5446 , and the mean square error (MSE) is 0.0321 . Based on the above settings, the following can be obtained.

The samples of the sports competition management behavior data from 2018 to 2020 are selected as the test data set to obtain the initial sample distribution sequence of the sports competition management data, as shown in Figure 2.

The above data are used as the test set to carry out data mining and movement prediction. The distribution of the characteristics of the raw data and the predicted distribution results are shown in Figure 3.

From Figure 3, it can be known that the convergence in the characteristic distribution of the data is good, and the disturbance error is low based on the data prediction of the sports competition management behaviors. Data mining technologies have become a great game-changer to education. Their prominent advantages are huge information capacity, strong interaction, good time efficiency, and high efficiency. They have offered tremendous development opportunities and open pathways for college and university sports management education, led to epoch-making changes to education, and also brought constructive enlightenment and ideas to educators.

5.2. Repetitive Utilization of High-Quality Education Videos. The most widespread application method in multimedia education is that physical education teachers use multimedia to present high-quality education video resources that are directly in line with the education content. For example, the teachers play the training videos taught by the international or domestic high-level professional team coaches based on the basketball education contents, such as the education videos on the running training of team members without the ball. In this case, the students will gain more and more professional knowledge and technical skills in this highly professional coaching with an excellent track record. Firstly, high-quality education videos are repeatedly used in physical education classroom education practice. For those innovative, high-quality education videos, the utilization by higher vocational physical education teachers for their education and the use of videos and the transcending spatial and temporal communication with the teachers of the course can not only achieve high-quality learning for students but also inspire the relevant teachers to carry out education and renovation in education and education technologies. Through the demonstration of those gymnasts or other excellent athletes, students can clearly understand the details of the movements and achieve breakthroughs in education difficulties. In this way, it can not only inspire and guide the students in their learning directly but also create practical entry points for teachers to make breakthroughs in their education process. Secondly, the school-based education and research of high-quality education videos are repeatedly applied. The videos on the sports competition management 


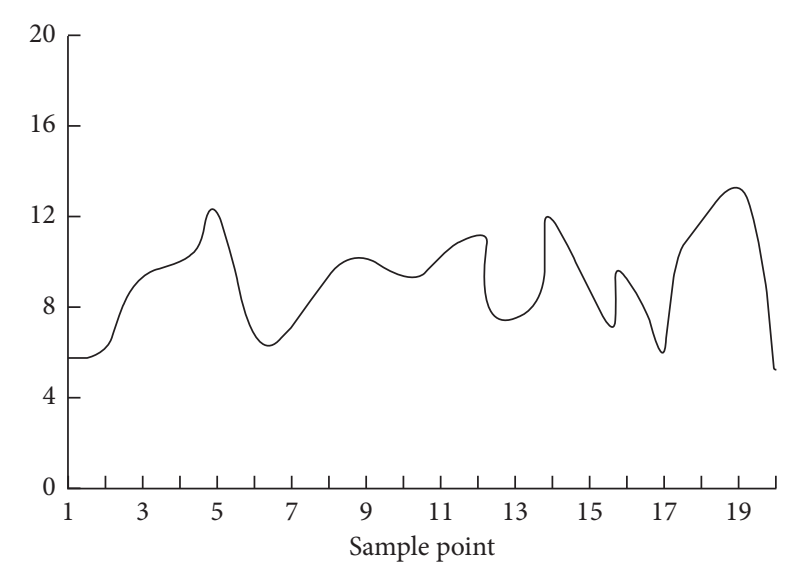

FIGURE 2: Sampling of the data information in the traditional sports competition management.

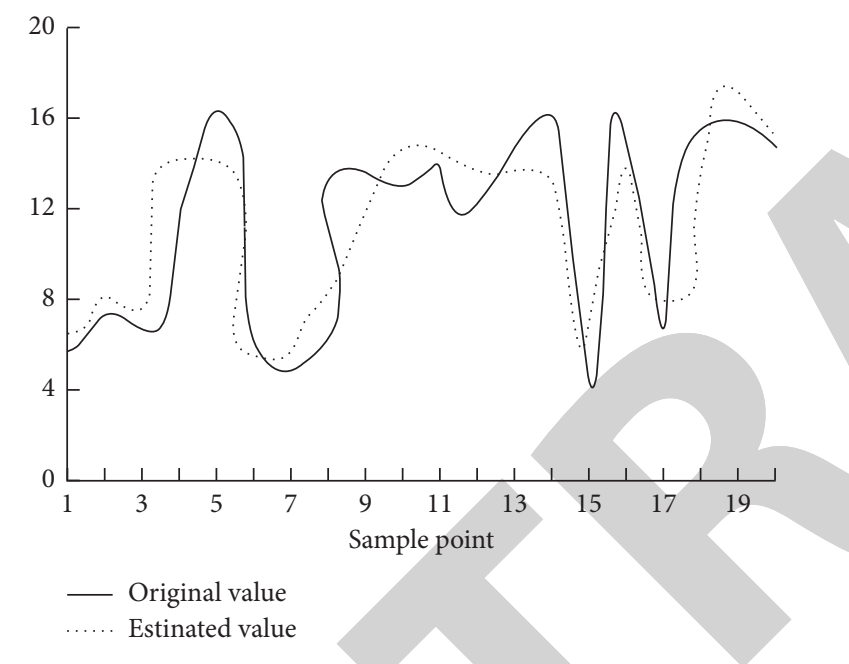

FIGURE 3: Predicted results of data mining in the sports competition management.

education quality are one of the optimal education and research original materials. Teachers can learn from the excellent elements through continuous watching and learning in the education application and the discussion of education and research. They can also identify the flaws and even deficiencies, summarize the experience, learn the lessons, and use or avoid them in their own education. With the accumulation of more and more multimedia education materials, the relevant education and research materials will become increasingly comprehensive, which can accumulate the most precious original education materials for the renovation of sports competition management education.

\subsection{Enhancement of the Intuitiveness and Vividness of Sports} Competition Management Education. In the education practice of sports competition management, multimedia demonstrations are more exciting and interesting than the instruction example by teachers. In particular, the coaches or demonstrators in the videos often have a nice style and can provide excellent guidance. The three-dimensional features of multimedia sound, color, shape, image, and pictures all present intuitive and impressive education contents, whether it is the explanation of knowledge or the demonstration of specific movements by animation or live-action videos. Firstly, the content and movement demonstration of education items in sports competition management is intuitive. In general, various movements are demonstrated through the application of multimedia sports competition management education in two ways. One way is to demonstrate the movements in the form of animation; that is, the teachers use FLASH or animation production approaches and use virtual characters to demonstrate the movements that need to be completed in sports management education. The second way is to playback the movement that needs to be taught in live video recording. The presentation method should be selected based on the preferences of teachers and students, as well as the proficiency of teachers in the application of multimedia technology. Secondly, the vivid contrast between correct and wrong sports technical movements is presented vividly. Physical education is a practical education activity based on technical skills. Due to the position of learning or the various understanding of the education language used by the teachers, there will always be differences in the details. In the application of multimedia education technology, various perspectives can also lead to differences in the reception of the relevant sports knowledge information in students. Hence, teachers can apply multimedia technology in the consolidation practice session for the students, such as recording videos of the practice by the students and playing the videos of accurate movements based on the learning situation of the students. In this way, the students can distinguish the right or wrong movements through comparison and make improvements according to the proper movements or requirements demonstrated by the teacher and in the video. The application of multimedia education has significantly reduced the workload of teachers in the explanation and demonstration of the correct movements and the illustration of the essentials of the aforesaid actions and helped the students achieve conscious learning guided by their interests.

\section{Conclusions}

The education reform of sports meeting management from the perspective of multimedia has been launched. There are not only efforts made in the step-by-step reforms in education but also bold renovations among schools in developed regions. For example, students in different schools carry out remote or online video interactive communications at the same time in the process of education, including remote or online communication through video interactive education between students taught by the same teacher and at different schools. Guided by various teachers, different students can carry out remote or online video education interactive communications. That is to say, the reform of sports meeting management education from the perspective of multimedia has demonstrated the high-tech feature based on more and more modern educational technologies, the relevance and vivid personal experience of students in the learning process, the renovation of teachers in the application of modern 
information and other technologies, the long-distance cooperation, and other advantages, which has created a more convenient platform for the development of sports competition management education and the reform of education.

\section{Data Availability}

The data used to support the findings of this study are available upon request to the author.

\section{Conflicts of Interest}

The author declares that there are no conflicts of interest.

\section{Acknowledgments}

This research study was sponsored by two projects. Project one: Humanities and Social Science Research Project of Hubei Education Department. The name of the project is Research on the Construction of Leisure Sports Major in Physical Education Colleges. The project number is 17Q149. Project two: Leisure Sports National First-Class Major Construction Funds. The paper is published for the conclusion of the project. The author would like to thank the projects for supporting this article.

\section{References}

[1] P. B. Reneta and D. H. Penny, "Information technology in sport management curricula," Journal of Educational Technology Systems, vol. 45, no. 3, pp. 326-342, 2017.

[2] J. Yin, "Constructing stereoscopic teaching mode of sports food based on information technology," Advance Journal of Food Science and Technology, vol. 10, no. 7, pp. 514-517, 2016.

[3] M. Szark-Eckardt and E. Bendíková, "Modern information technology as an instrument used in sport, tourism and recreation to build a healthy society," AIP Conference Proceedings, vol. 1906, 2017.

[4] Z. Zhang, "Research on sports information technology education platform based on asp-net technology," The Open Cybernetics \& Systemics Journal, vol. 9, no. 1, pp. 2989-2993, 2015.

[5] S. Zhang, "Sports public service system based on fpga and convolutional neural network," Microprocessors and Microsystems, vol. 5, no. 5, pp. 19-26, Article ID 103475, 2020.

[6] Y. Xie, J. Zhang, and Y. Xia, "Semi-supervised adversarial model for benign-malignant lung nodule classification on chest ct - sciencedirect," Medical Image Analysis, vol. 57, pp. 237-248, 2019.

[7] Y. L. Lin and C. H. Kao, "A study on the policy of sport for all in taiwan from the perspective of the new public service," Asian Sports Management Review, no. 10, pp. 2-10, 2016.

[8] Y. Hu, "Realization of intelligent computer aided system in physical education and training," Computer-Aided Design and Applications, vol. 18, pp. 80-91, 2020.

[9] Q. Guo and B. Li, "Role of ai physical education based on application of functional sports training," Journal of Intelligent and Fuzzy Systems, vol. 40, no. 2, pp. 1-9, 2020.

[10] Gaobin, H. N. Cao, and Z. Z. Liu, "An artificial intelligence fuzzy system for improvement of physical education teaching method," Journal of Intelligent and Fuzzy Systems, vol. 40, no. 1, pp. 1-10, 2020.
[11] Z. Liu, "Analysis of physical education evaluation system and design of intelligent evaluation system," Boletin Tecnico/ Technical Bulletin, vol. 55, no. 17, pp. 414-417, 2017.

[12] J. Harmer, “The practice of English language teaching," ELT Journal, vol. 32, no. 4, pp. 401-405, 2016.

[13] M. Ghadiri, M. Tavakoli, and S. Ketabi, "Development of a criticality-oriented English teaching perceptions inventory (cetpi) and exploring its internal consistency and underlying factor structure," Current Psychology, vol. 34, no. 2, pp. 268-281, 2015.

[14] J. J. Yue and G. Chen, "Competence of pharmacy mentors: a survey of the perceptions of pharmacy postgraduates and their mentors," BMC Medical Education, vol. 44, no. 2, pp. 113-117, 2020.

[15] Y. Xi and L. Dong, "Study on the intelligent evaluation system design of sports teaching," Boletin Tecnico/Technical Bulletin, vol. 55, no. 4, pp. 125-131, 2017.

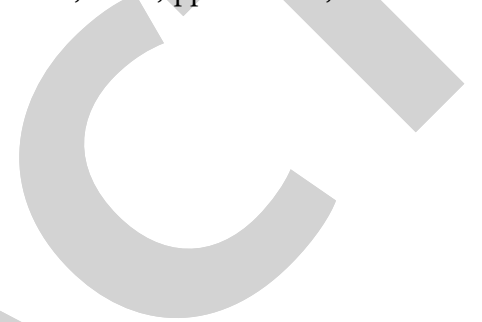

